\title{
Arcabouço estrutural e microestruturas do minério de ferro da jazida Casa de Pedra, Quadrilátero Ferrífero, MG
}

\author{
Barbara Trzaskos ${ }^{1}$, Fernando Flecha Alkmim² \& Guilherme Zavaglia ${ }^{3}$
}

\begin{abstract}
Resumo A Mina de Casa de Pedra, localizada no extremo sudoeste do Quadrilátero Ferrífero, MG, foi submetida a uma investigação estrutural de detalhe, através da qual foi possível conhecer o seu acervo de estruturas, assim como a sua evolução tectônica. Neste estudo procurou-se entender de que forma o arcabouço estrutural da mina influencia nas variações dos atributos intrínsecos de seus componentes: mineralogia, porosidade, granulometria e textura. Foram obtidos os seguintes resultados: unidades expostas na área da mina e arredores foram submetidas a três eventos deformacionais; as frentes de lavra Corpo Oeste e Corpo Principal estão situadas em distintos domínios estruturais e seus minérios exibem diferentes atributos mineralógicos; o minério de ferro proveniente do Corpo Oeste tende a ser mais rico em hematita especular e goethita, com porosidade média de $17 \%$, enquanto que o Corpo Principal tende a ser constituído predominantemente por hematita granular e magnetita, com porosidade média de $20 \%$. Desta forma, pode-se concluir que o arcabouço estrutural condiciona significativamente as características composicionais, texturais e microestruturais dos minérios de ferro.
\end{abstract}

Palavras-chave: minério de ferro, Quadrilátero Ferrífero, geologia estrutural, microtectônica.

\begin{abstract}
Structural framework and microstructures of iron ores of the Casa de Pedra mine, Quadrilátero Ferrifero, MG. The Casa de Pedra mine, located in the southwestern portion of the Quadrilátero Ferrífero (Iron Quadrangle), Minas Gerais state, Brazil, was subject to a detailed structural investigation, allowing the characterization of its tectonic evolution. The main goal of the study was to check in what extent tectonic structures control the iron ore properties such as mineralogical composition, porosity, grain size and texture. We obtained the following results: rocks units exposed in the mine and surrounding areas underwent three deformational events; the Western and Main ore bodies of the Casa de Pedra mine are located in distinct structural domains, which exhibit different mineralogical attributes; iron ores from Western body tends to be richer in specularite and goethite, and show $17 \%$ porosity, whist the Main body is made up mainly of granular hematite and magnetite, with $20 \%$ porosity. We concluded that tectonic structures indeed exert a significant control on mineralogical composition, textures and microstructures of the iron ores.
\end{abstract}

Keywords: iron ore, Iron Quadrangle, structural geology, microtectonics.

INTRODUÇÃo No final da década de 1970 teve início no Quadrilátero Ferrífero $(\mathrm{QF})$ uma série de investigações estruturais de detalhe, acompanhadas de farta documentação de microestruturas e processos de transformações metamórficas sin e pós-deformacionais de minérios de ferro de vários depósitos da região. Dentre outros, citam-se os trabalhos de Eichler (1976), Hackspacker (1979), Rosière (1981) e Chemale Jr. et al. (1987).

Uma das conclusões mais importantes destes estudos é que a composição mineralógica e as microestruturas dos minérios ferro do Quadrilátero Ferrífero são controladas pela posição que o depósito ocupa nas grandes estruturas regionais, a qual, via de regra, reflete as condições regionais de deformação e metamorfismo. Além disso, em segunda instância, os atributos dos minérios são controlados pela posição que ocupam nas estruturas menores em escala de mina.

Investigações mais recentes (Stephenson 1980, Leone et al. 1981, Rosière 1992, Xavier 1994, Zavaglia 1995, Rosière et al. 1995, Varajão 1996, 1997, Santiago 2000) demonstraram que o comportamento dos minérios de ferro do QF, nos processos de beneficiamento e siderúrgicos, sofre grande influência da composição mineralógica e dos atributos texturais e estruturais. Portanto, para um melhor controle de qualidade e para que se possa prever o comportamento dos minérios de ferro nos processos de beneficiamento e metalúrgicos, é imprescindível a análise estrutural de detalhe desses depósitos.

A Mina de Casa de Pedra localiza-se na porção sudoeste do QF (Fig. 1), distando cerca de $8 \mathrm{~km}$ da cidade de Congonhas do Campo. Do ponto de vista

1 - Programa de Pós-Graduação em Geologia, Departamento de Geologia, Escola de Minas, Universidade Federal de Ouro Preto, Ouro

Preto (MG), Brasil. E-mail: barbaratrzaskos@gmail.com

2 - Departamento de Geologia, Escola de Minas, Universidade Federal de Ouro Preto, Ouro Preto (MG), Brasil. E-mail:

alkmim@degeo.ufop.br

3 - ArcelorMittal, Ouro Preto (MG), Brasil. E-mail: guilhermeg.zavaglia@arcelormittal.com.br 
geológico, a jazida está situada em um setor de grande complexidade estrutural do Quadrilátero Ferrífero, com influência do Sinclinal de Dom Bosco, de orientação geral E-W, e do Sinclinal da Moeda, cujo traço axial é aproximadamente N-S (Fig. 1).

Na Mina de Casa de Pedra a lavra se dá em dois corpos de minérios supergênicos chamados Corpo Oeste e Corpo Principal, hospedados na Formação Ferrífera Bandada Cauê, do Supergrupo Minas, de idade paleoproterozoica. A mina, de propriedade da Companhia Siderúrgica Nacional (CSN), produz minérios de ferro desde 1946 para atender a Usina Presidente Vargas, instalada em Volta Redonda, RJ.

Objeto dos estudos pioneiros de Barbosa (1949), Guimarães e Belezkij (1953), Guild (1953, 1957) e Dorr (1969), a Mina de Casa de Pedra e suas encaixantes ainda não tinham sido submetidas a uma investigação estrutural de detalhe, que explorasse o relacionamento entre trama deformacional e os atributos dos minérios. No presente trabalho, são descritos o arcabouço estrutural e a história tectônica do depósito de Casa de Pedra e, a seguir, mostra-se de que maneira estes aspectos influenciam nos atributos intrínsecos do minério de ferro explotado.

CONTEXTO GEOLÓGICO REGIONAL A porção sudoeste do Quadrilátero Ferrífero é marcada pela junção entre duas estruturas regionais, os sinclinais
Moeda e Dom Bosco, onde também se faz presente um grande número de falhas de empurrão e transcorrentes, como pode ser observado no mapa simplificado da figura 2. Esse quadro de complexidade estrutural já havia sido enfatizado nos trabalhos pioneiros de Barbosa (1949) e Guimarães e Belezkij (1953) e, mais tarde, detalhado através da cartografia de Guild (1957) e Ladeira (1997). Nessa região, estão presentes todas as unidades que compõem a coluna estratigráfica do Quadrilátero Ferrífero (Fig. 3), desde o Complexo Metamórfico do embasamento e o Supergrupo Rio das Velhas, ambos de idade arqueana, até as unidades de idade paleoproterozoica do Supergrupo Minas e Grupo Itacolomi.

Os sinclinais da Moeda e Dom Bosco (Fig. 2), de traços axiais respectivamente NS e EW, envolvem toda a assembleia de rochas supracrustais do QF e alojam-se entre as estruturas dômicas do Bonfim, a oeste, do Bação, a nordeste, e do plúton de Alto Maranhão, a sul (Guild 1957, Dorr 1969, Noce 1995, Endo 1997) (Fig. 2). Nos domos do Bonfim e do Bação, afloram litotipos do Complexo Metamórfico arqueano (Teixeira 1982, Carneiro 1992, Noce 1995), enquanto o plúton de Alto Maranhão corresponde a um corpo granodiorítico de idade paleoproterozoica $(2,124 \mathrm{Ga})$ (Noce 1995). Um leque de falhas de empurrão, associadas a dobras vergentes para WSW, secciona todo o pacote supracrustal e é truncado, a sul pela, Falha do Engenho (Guild 1957, Dorr 1969) (Fig.2).

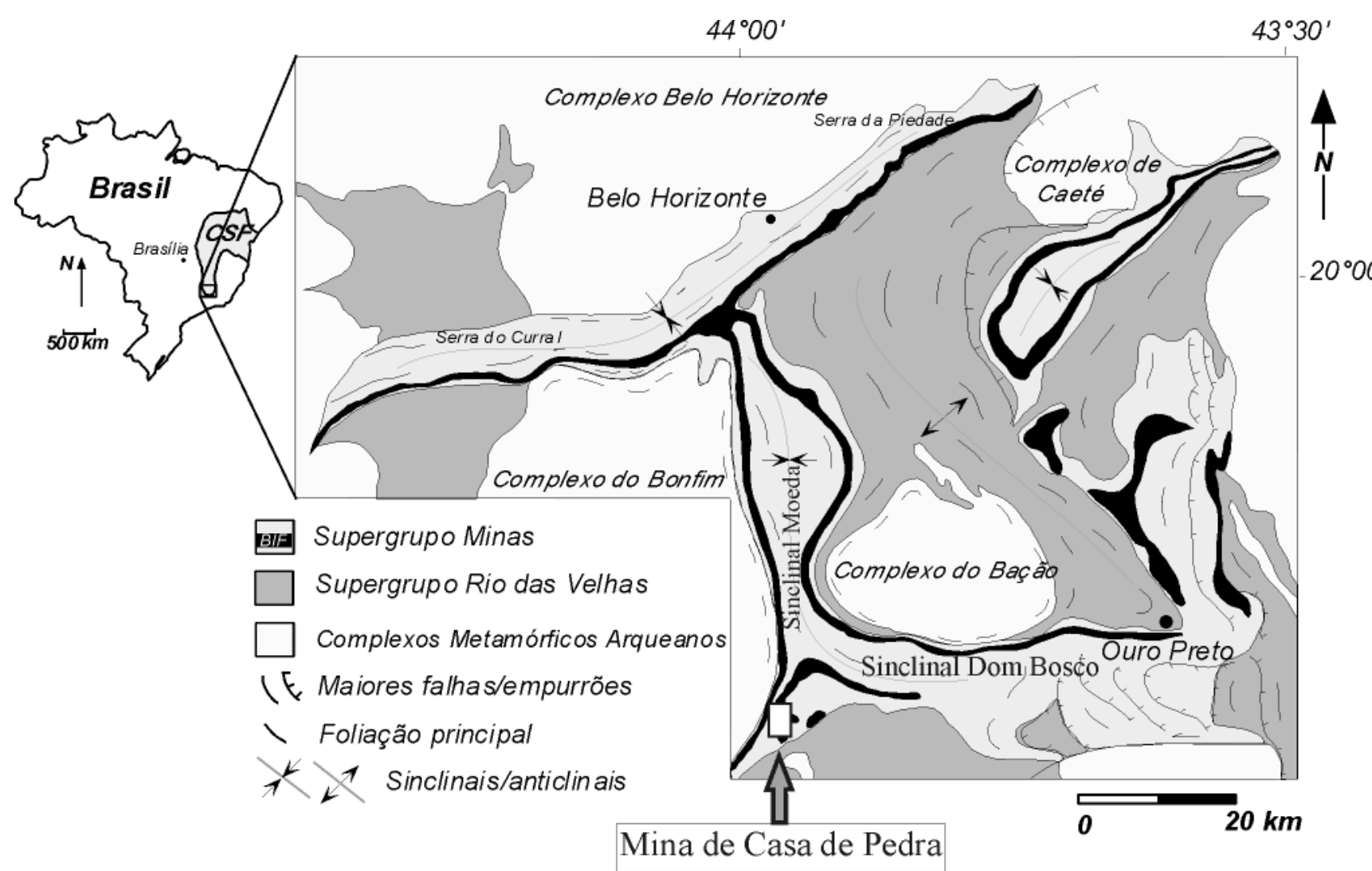

Figura 1 - Mapa geológico simplificado do Quadrilátero Ferrífero, mostrando a localização da área de estudo (extraído de Lagoeiro 2000, modificado de Dorr 1969). 


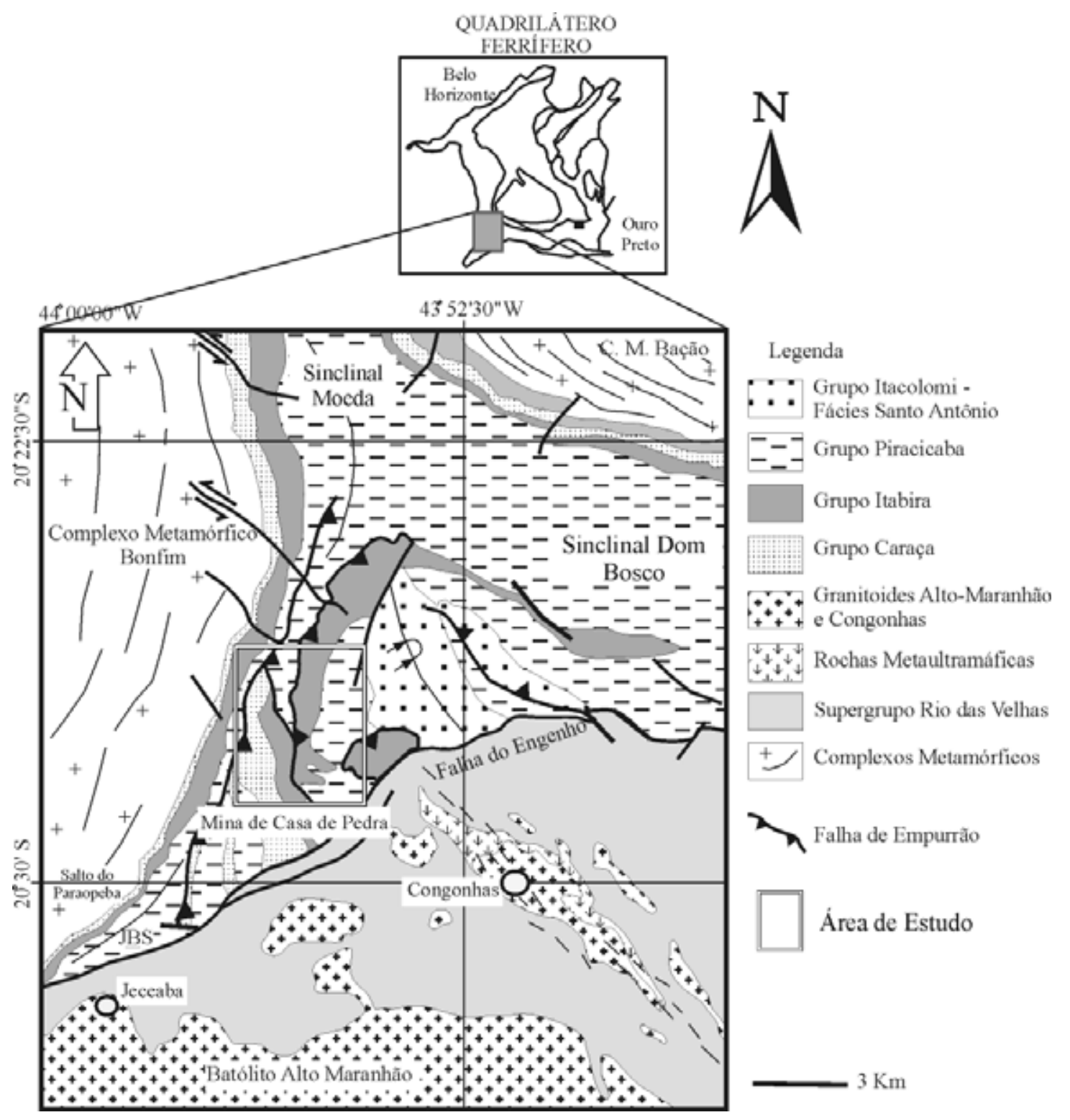

Figura 2 - Mapa geológico da porção sudoeste do Quadrilátero Ferrífero com a localização da área de estudo (extraído de Endo 1997, modificado de Dorr 1969).

Para a investigação estrutural de detalhe delimitou-se uma área retangular de $19,3 \mathrm{~km}^{2}$, que engloba o depósito de Casa de Pedra e suas adjacências imediatas (Fig. 4). Nessa área, afloram rochas dos supergrupos Rio das Velhas e Minas, além de intrusivas máficas pós-Minas. Clorita-xistos e filitos alterados, do Grupo Nova Lima (Supergrupo Rio das Velhas), cavalgam a Formação Ferrífera Cauê (Supergrupo Minas) na porção sudeste da área estudada (Fig. 4). O Supergrupo Minas é representado pelos grupos Caraça, Itabira e Piracicaba (Figs. 3 e 4). O Grupo Caraça se faz presente pelos quartzitos sericíticos e localmente conglomeráticos da Formação Moeda e pelos filitos cinza, sericíticos e hematíticos da Formação Batatal. Ambos afloram de modo contínuo em todo o setor oeste da área de estudo (Fig. 4).

Em conjunto, as formações Cauê e Gandarela (Grupo Itabira) ocupam a maior parte da área de estudo. A Formação Cauê consiste de itabiritos silicosos, carbonáticos, anfibolíticos e manganesíferos, e de minérios de ferro hematíticos de alto teor, que afloram em três setores distintos da área investigada (Fig. 4). $\mathrm{Na}$ sua porção oeste, recobrem, em contato gradacional, os filitos da Formação Batatal, tomando parte de uma estrutura homoclinal de direção variável entre NS e NNW-SSE. Nessa estrutura está encaixado o Corpo Oeste da Mina de Casa de Pedra (Figs. 4 e 5). Ao longo de uma faixa, também orientada segundo N-S da metade norte da área estudada, situa-se o bloco de capa da Falha de Empurrão da Serra do Mascate (Figs. 4 e 5). Neste setor, a Formação Cauê justapõe-se a um sill de rocha máfica a oeste e a um dique, a sul. A leste é recoberta por carbonatos da Formação Gandarela e folhelhos das formações Cercadinho e Fecho do Funil (Figs. 4 e 5). A terceira zona de exposição, localizada 


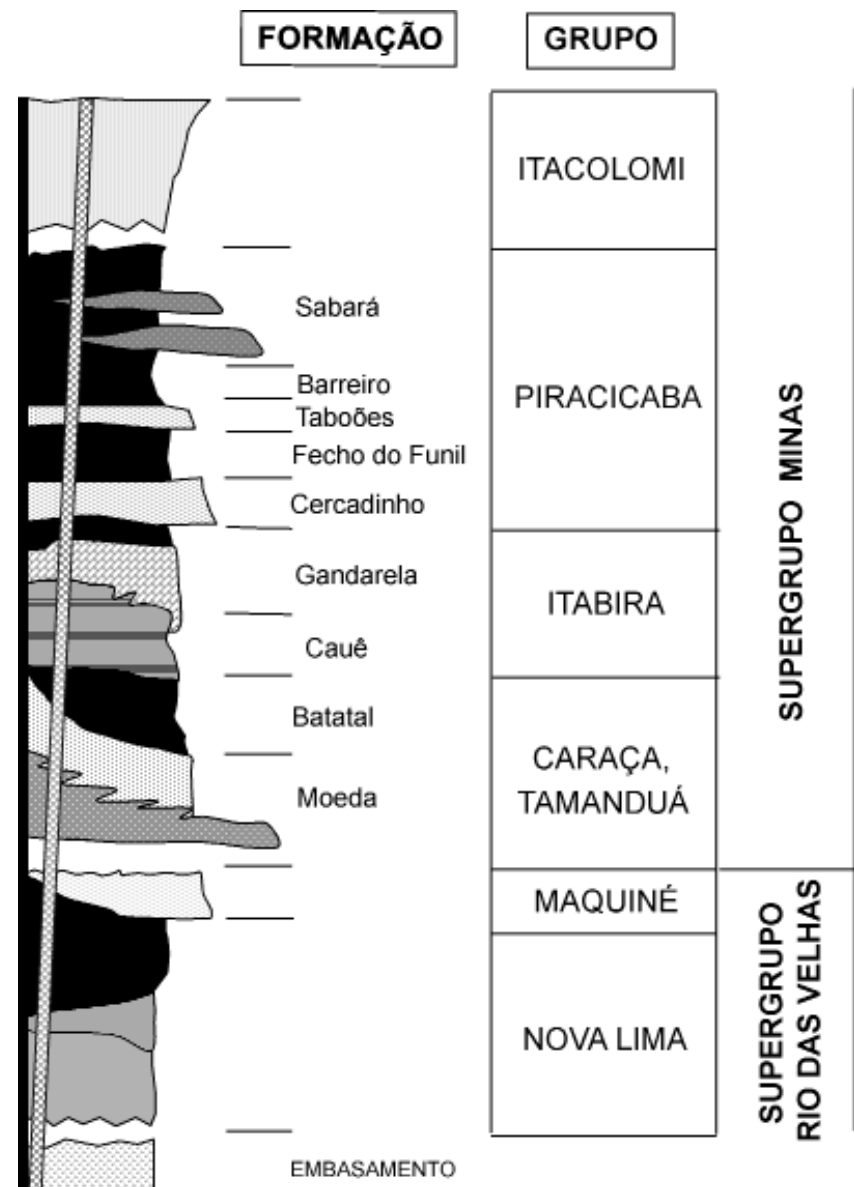

Figura 3 - Coluna estratigráfica esquemática da região do Quadrilátero Ferrifero, compilada a partir de Dorr (1969) e Marshak \& Alkmim (1989).

na porção central da área de estudo, exibe grande complexidade estrutural, é limitada por falhas e engloba o Corpo Principal da Mina de Casa de Pedra (Figs. 4 e 5).

ARCABOUÇO ESTRUTURAL E EVOLUÇÃO TECTÔNICA DA ÁREA DE ESTUDO Do ponto de vista estrutural, dois grandes compartimentos, aqui designados A e B, podem ser distinguidos na Mina de Casa de Pedra e arredores (Fig. 4). O limite entre os dois compartimentos foi inferido com base em observações de campo, feitas ao longo de perfis transversais às estruturas. A transição entre os compartimentos $\mathrm{A} e$ B é marcada por mudanças de estilo e significado cinemático das estruturas presentes.

O Compartimento A (Fig. 4), que representa a aba oeste do Sinclinal da Moeda e contém várias repetições das unidades por falha de empurrão, engloba a zona de contato tectônico das rochas do Supergrupo Minas com os gnaisses arqueanos do Domo do Bonfim. A área de estudo cobre uma pequena parte desse compartimento (Fig. 4), onde os metassedimentos Moeda, Batatal e Cauê compõem, superpostos, um homoclinal de direção geral NNW-SSE e mergulho de cerca de $45^{\circ}$ para ENE (Figs. 4 e 5). Em todo esse compartimento (exceto nas zonas de falhas de empurrão), as rochas apresentam uma foliação subparalela ao acamamento $\left(\mathrm{S}_{0}\right)$ e uma significativa lineação de estiramento orientada preferencialmente segundo $111 / 40^{\circ}$ (Figs. 6a e b). Indicadores cinemáticos, associados a essas estruturas, indicam movimentação geral normal dextral para todo o conjunto, incluindo a zona de cisalhamento alojada no contato entre o embasamento e o Supergrupo Minas.

O Compartimento $\mathrm{B}$ (Fig. 4) corresponde à porção sul da zona de junção entre os sinclinais Moeda e Dom Bosco, marcada por um conjunto de falhas de rejeito oblíquo, reversas sinistrais e dobras vergentes para WSW. Engloba os corpos Oeste e Principal da Mina de Casa de Pedra. Este compartimento tem como elementos tectônicos característicos uma foliação penetrativa $\left(\mathrm{S}_{2}\right)$, orientada preferencialmente segundo $098 / 54^{\circ}$, sobre a qual se desenvolve uma lineação de estiramento cuja posição modal é $102 / 47^{\circ}$ (Figs. 7a e b). Estas estruturas estão associadas a uma movimentação geral reversa e reversa sinistral.

História da Deformação Tomando por base o levantamento estrutural de detalhe realizado na área de estudo e a literatura a respeito da evolução tectônica do Q.F., conclui-se que as estruturas tectônicas presentes na região da Mina de Casa de Pedra foram geradas em três eventos distintos, que envolvem quatro fases deformacionais, aqui designadas $\mathrm{D}_{1}, \mathrm{D}_{2}, \mathrm{D}_{3}$ e $\mathrm{D}_{4}$.

Durante o Evento $\mathrm{E}_{1}$, fase $\mathrm{D}_{1}$, foram gerados os elementos tectônicos característicos do Compartimento A. Em função da sua natureza, distribuição espacial (adjacentes ao Domo do Bonfim) e cinemática (normal dextral), podem ser interpretados como resultantes do processo de formação das grandes estruturas regionais do Q.F., ou seja, desenvolvimento dos domos e dos sinclinais a eles associados Moeda e Dom Bosco. Chemale Jr. et al. 1991, Hippert et al. 1992, Endo \& Nalini Jr. 1992, Endo 1997, Marshak et al. 1992 e Alkmim \& Marshak 1998 caracterizam essas estruturas como produto de um regime distensional que daria origem a província de domos e quilhas, que é o Quadrilátero Ferrífero. Datações Sm-Nd realizadas em auréola de metamorfismo de contato, associada à ascensão de um dos domos do norte do Quadrilátero Ferrífero, indicaram idade de $2098+33 \mathrm{Ma}$ (Bruckner et al. 2000), o que permitiu relacioná-la ao Evento Transamazônico.

As fases $\mathrm{D}_{2}$ e $\mathrm{D}_{3}$, co-axiais e progressivas, são aqui interpretadas como relativas a um mesmo evento $\mathrm{E}_{2}$ em resposta a um campo compressional orientado, segundo WNW-ESSE, que deu origem ao transporte tectônico geral para WNW. A estas fases está relacionada uma rica assembleia de estruturas que são características do Compartimento B e que englobam a Mina de Casa de Pedra e encaixantes. Tais fases têm sido vistas no Q.F. como resposta a um campo compressional, atribuído por alguns autores ao evento Brasiliano (p.ex. Chemale et al. 1991 e Alkmim \& Marshak 1998). Para Endo, (1997) tais estruturas teriam sido nucleadas no Segundo Megaevento do Ciclo Transamazônico, 


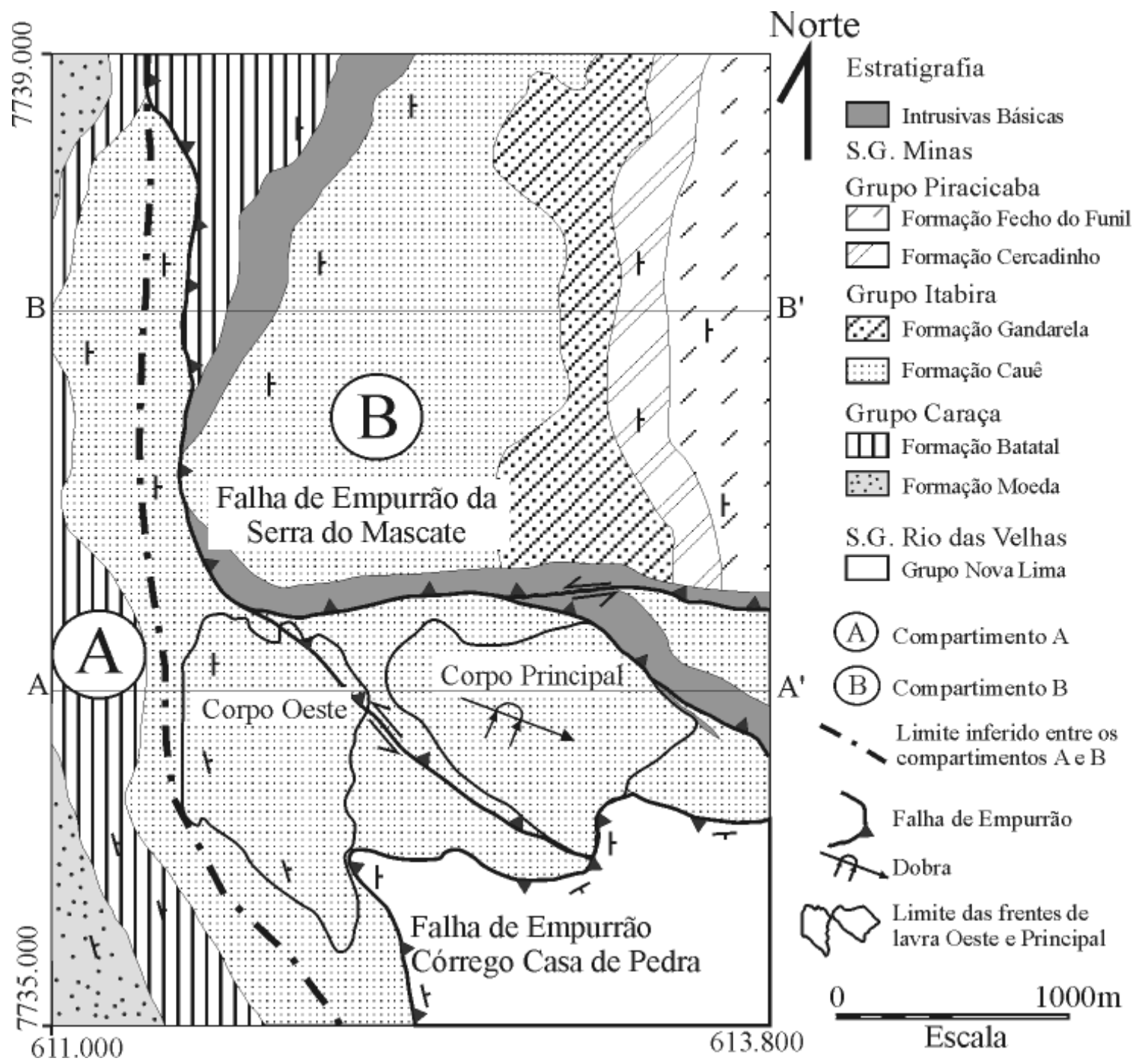

Figura 4 - Mapa geológico simplificado da região da Mina de Casa de Pedra.

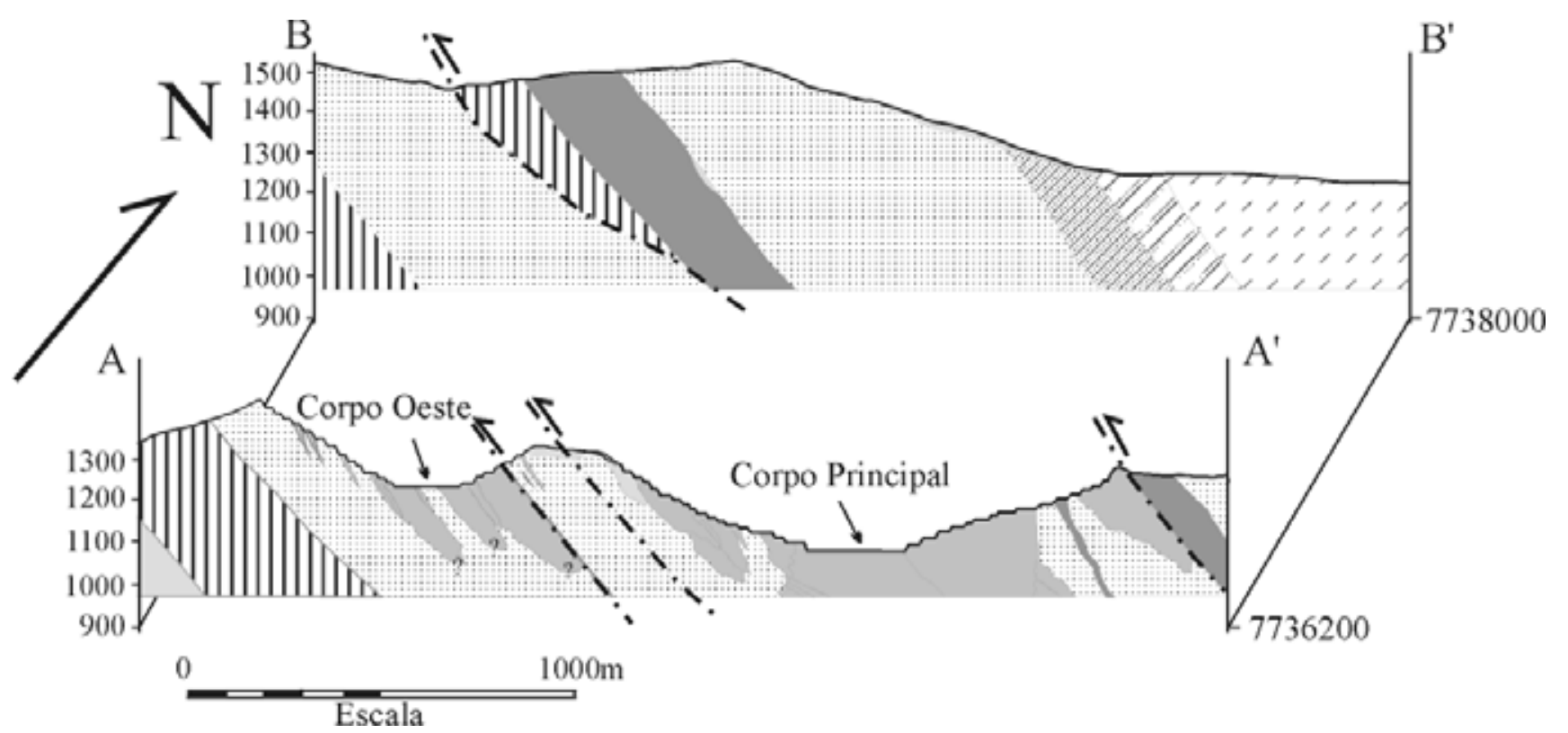

Figura 5 - Seções geológicas da região da Mina de Casa de Pedra. Localização na figura 4. 

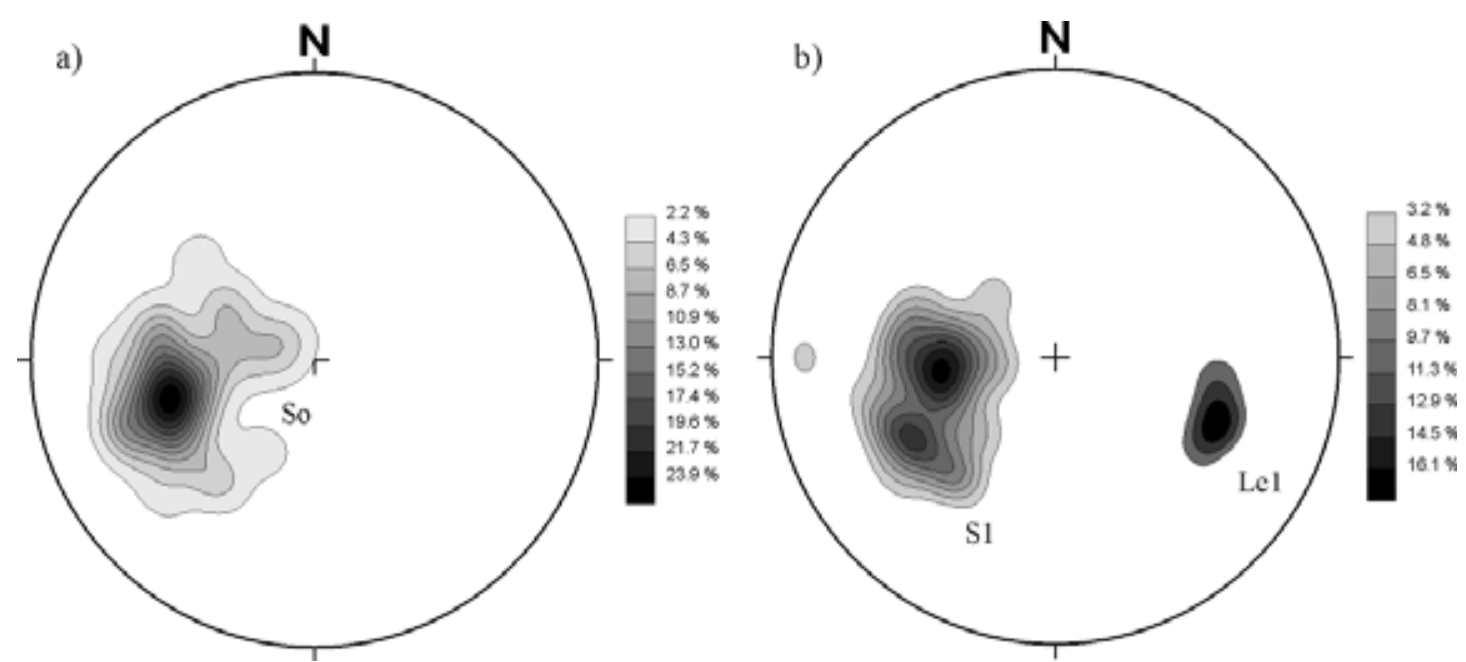

Figura 6 - Diagramas estereográficos sinópticos dos elementos tectônicos característicos do Compartimento A. (a) Acamamento (So). Total de medidas: 42; máximo: 075/44º(23,9\%). (b) Foliação $S_{I}$. Total de medidas: 62; máximo: $062 / 45^{\circ}(19,4 \%)$. (c) Lineação de estiramento Le ${ }_{1}$ Total de medidas: 15; máximo: 111/40 $(33 \%)$.
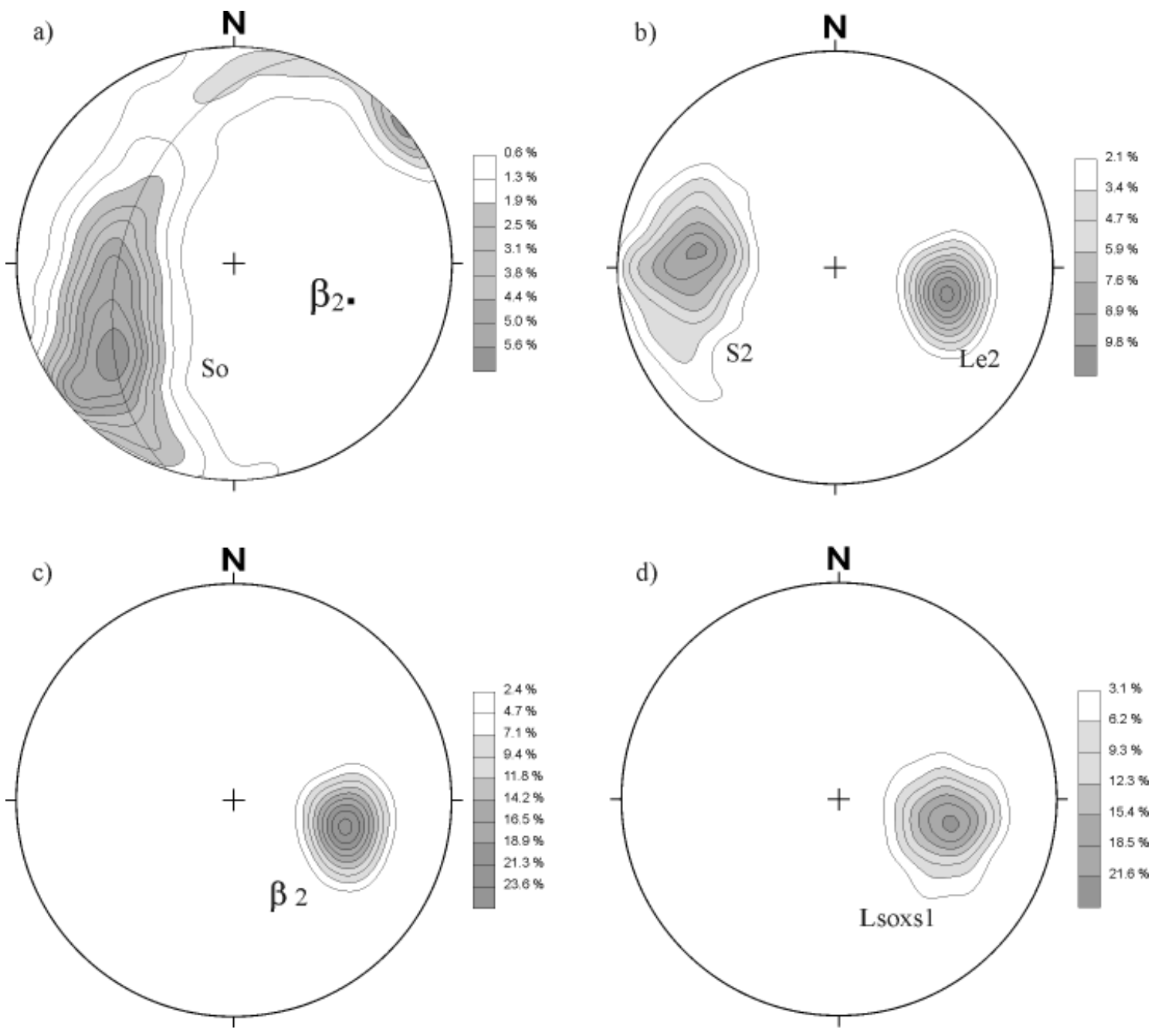

Figura 7 - Diagramas estereográficos sinópticos dos elementos tectônicos característicos do Compartimento B. (a) Acamamento So. Total de medidas: 1.425 ; máximo: 052/59 $(5,6 \%)$. (b) Foliação $S_{2}$ Total de medidas: 401; máximo: 098/54 (9,8\%). Lineação de estiramento Le 2 Total de medidas: 480; máximo: $102 / 47^{\circ}\left(30^{\circ} \%\right)$. (c) Charneira de dobras $F_{2}$ Total de medidas: 146; máximo: 103/46 $(23,6 \%)$. (d) Lineação de interseção Lso S $_{1 .}$ Total de medidas: 162; máximo: 102/46 $(21,6 \%)$. 
caracterizado por um movimento de massa de SE para NW, que teria lugar entre 2059 e $1900 \mathrm{Ma}$. Esse evento compressional teria sido responsável pela amplificação e forma final dos sinclinais Moeda e Dom Bosco.

A fase $D_{4}$ é relativa a um evento extensional $E_{3}$ que gerou falhas normais com direção $\mathrm{E}-\mathrm{W}$, as quais, na porção central do Compartimento $\mathrm{B}$, constituem um gráben onde houve a deposição de sedimentos ferruginosos, os quais se apresentam totalmente laterizados. De acordo com Lipski et al. (2001) estas estruturas são, provavelmente, de idade Terciária.

O Acervo Estrutural da Jazida de Casa de Pedra Os corpos de minério da Mina de Casa de Pedra e suas encaixantes, integrantes do Compartimento $\mathrm{B}$, exibem como elementos tectônicos dominantes um rico acervo de estruturas compressionais, geradas nas fases $\mathrm{D}_{2}$ e $\mathrm{D}_{3}$ do Evento $\mathrm{E}_{2}$. As estruturas macro e microscópicas geradas no evento deformacional $\mathrm{E}_{1}$, fase $\mathrm{D}_{1}$, não foram reconhecidas na área da mina, tendo sido provavelmente obliteradas nas fases deformacionais posteriores.

ESTRUTURAS DA FASE $D_{2}$ Dentre as estruturas da fase $\mathrm{D}_{2}$, as dobras $\mathrm{F}_{2}$ exibem comprimento de onda que variam da escala microscópica à centena de metros e podem ser classificadas como assimétricas, fechadas a apertadas e, localmente, isoclinais. Mostram vergência sistemática para WSW e estão desenvolvidas sobre o bandamento primário $\mathrm{S}_{0}$. Em regiões onde a deformação foi mais intensa, apresentam-se isoclinais com flancos rompidos e, às vezes, com as charneiras isoladas. Às dobras $\mathrm{F}_{2}$ associa-se a foliação plano axial $\mathrm{S}_{2}$. Os eixos das dobras $\mathrm{F}$, mostram caimento para ESE, com atitude modal $103 / 46^{\circ}$ (Fig. 7c). No diagrama sinóptico do acamamento, obteve-se um eixo $\beta_{1}$ de orientação $105 / 45^{\circ}$ coincidente com os valores medidos (Fig. 7a). O melhor exemplo de dobra desta geração pode ser dado pela estrutura envoltória do Corpo Principal. Trata-se de um sinforme anticlinal ligeiramente cônico vergente para SW com eixo posicionado em 101/45 ${ }^{\circ}$. Seu comprimento de onda é de aproximadamente 800 m (Figs. 4 e 5).

A foliação $\mathrm{S}_{2}$, posicionada no plano axial das dobras $\mathrm{F}_{2}$, é marcada pela forte orientação preferencial planar dos constituintes das rochas. Na Formação Ferrífera Cauê, a foliação $\mathrm{S}_{2}$, via de regra, está paralela ao acamamento, revelando as magnitudes de deformação relativamente maiores exibidas por estas rochas. Em domínios menos deformados, apresenta-se como uma foliação transversal, com traços incipientes, oblíquos ao acamamento. Microscopicamente é marcada pela orientação preferencial de cristais de especularita, agregados de quartzo e filossilicatos, paralelamente ou obliquamente ao acamamento, dependendo da posição considerada ao longo do arco das dobras $\mathrm{F}_{2}$. A foliação $\mathrm{S}_{2}$ orienta-se preferencialmente segundo $098 / 54^{\circ}$, tal como mostra o diagrama estereográfico da Fig. $7 \mathrm{~b}$.

A lineação de estiramento mineral $\mathrm{Le}_{2}$ está intimamente associada à foliação $\mathrm{S}_{2}$, da qual é componente.
Expressa-se nas formações ferríferas por uma tênue orientação preferencial de cristais de hematita e por um nítido arranjo linear de agregados alongados de quartzo; nos quartzitos e filitos, pela orientação preferencial dos eixos dos agregados e porfiroclastos de quartzo. O diagrama sinóptico da lineação de estiramento $\mathrm{Le}_{2}$ (Fig. $7 b$ ) indica sua orientação em $102 / 47^{\circ}$. Assim como em quase todo QF, verifica-se, na Mina de Casa de Pedra, o paralelismo entre a lineação de estiramento $\mathrm{Le}_{2} \mathrm{e}$ os eixos da dobras $\mathrm{F}_{2}$ (compare Figs. $7 \mathrm{~b}$ e c), fato já descrito e discutido por vários autores, dentre os quais Endo (1988), que o interpreta como resultado de deformação cisalhante oblíqua atuando sobre estratos originalmente não horizontais.

A lineação de interseção $\left(\operatorname{Ls}_{o x} s_{2}\right)$ é mais expressiva nos setores de baixa intensidade da deformação e nas zonas de charneira das dobras $F_{2}$. É mais proeminente nas formações ferríferas, sendo especialmente bem desenvolvida na zona de charneira do grande sinforme do Corpo Principal. A orientação principal dessa estrutura é $102 / 46^{\circ}$, paralela às charneiras das dobras $F_{2}$ e à lineação de estiramento Le2 (Fig. 7d).

Geneticamente relacionadas às estruturas anteriormente descritas, tem-se duas grandes falhas de empurrão e um conjunto de falhas menores arranjadas em um duplex de rejeito oblíquo, reverso sinistral (Figs. 4 e 5). A Falha do Córrego de Casa de Pedra, de traço bastante sinuoso em mapa, lança xistos do Grupo Nova Lima sobre a Formação Ferrífera Cauê na porção sudeste da área investigada. A Falha da Serra do Mascate, na porção norte da área, possui um segmento frontal orientado na direção NS e um segmento lateral (reverso sinistal) alojado em um dique máfico de orientação EW. Promove, naquele setor, a repetição do Filito Batatal e da Formação Ferrífera Cauê, como também a ocorrência das formações mais jovens, Gandarela, Cercadinho e Fecho do Funil.

Entre as falhas da Serra do Mascate e do Córrego Casa de Pedra, e a elas articulado, tem-se um conjunto de falhas de traço sigmoidal e de rejeito oblíquo reverso sinistral, compondo um arranjo em duplex oblíquo (Fig. 4). No interior do duplex, a Formação Ferrífera Cauê apresenta-se intensamente dobrada (Fig. 7a), destacando-se ali um sinforme anticlinal ligeiramente cônico, vergente para SW, que tem seu eixo posicionado em $101 / 45^{\circ}$ e envolve todo o Corpo Principal da Mina de Casa de Pedra.

ESTRUTURAS DA FASE $D_{3}$ No decorrer da Fase $\mathrm{D}_{3}$, formaram-se dobras, kink bands e uma clivagem de crenulação. As dobras $\mathrm{F}_{3}$, cujo comprimento de onda varia de $10 \mathrm{~cm}$ a $25 \mathrm{~m}$, podem ser classificadas como suaves e abertas, assimétricas e vergentes para W. Tem os seus eixos orientados preferencialmente no rumo NNE. Estão associadas a uma rica família de kinks que localmente evoluem para dobras em caixa.

A clivagem $\mathrm{S}_{3}$ ocorre nos filitos da Formação Batatal, na forma de uma descontinuidade não penetrativa, constituída por microfraturas evoluindo localmente 
para uma clivagem de crenulação com orientação geral 095/30 .

\section{Estrutura Interna e Geometria 3D dos Corpos Oes-} te e Principal Os corpos Oeste e Principal da Mina de Casa de Pedra estão situados em distintos domínios estruturais do Compartimento B (Fig. 4). O Corpo Oeste insere-se em uma estrutura homoclinal de direção geral NNW que mergulha para leste com cerca de $50^{\circ}$. O bandamento da Formação Ferrífera tem atitude modal de $084 / 50^{\circ}$, sendo praticamente coincidente com a foliação dominante $S_{2}$, cuja atitude modal é 095/60 (Fig. 8a). Dobras $F_{2}$ são raras e em função da relação entre estas estruturas o Corpo Oeste é caracteristicamente constituído por S-tectonitos (Fig. 9).

Por outro lado, o Corpo Principal, limitado por falhas de rejeito oblíquo, engloba o arco completo de um sinforme anticlinal reclinado, cujo eixo tem a atitude $100 / 46^{\circ}$. Nessas condições, o bandamento da formação ferrífera, intensamente plissado por dobras macroscópicas parasíticas, é truncado pela foliação dominante $\mathrm{S}_{2}$ (Fig. 8b). Como resultado da grande expressão da lineação de intersecção paralela à lineação de estiramento e posicionada em $102 / 47^{\circ}$ (Fig. 8b), os minérios do Corpo Principal apresentam-se como L-tectonitos (Fig. 9).

COMPOSIÇÃO MINERALÓGICA, TEXTURAS E MICROESTRUTURAS DO MINÉRIO DE FERRO $\mathrm{O}$ estudo petrográfico dos minérios de ferro foi realizado em 100 amostras da faixa granulométrica correspondente ao minério granulado, ou seja, da fração retida na

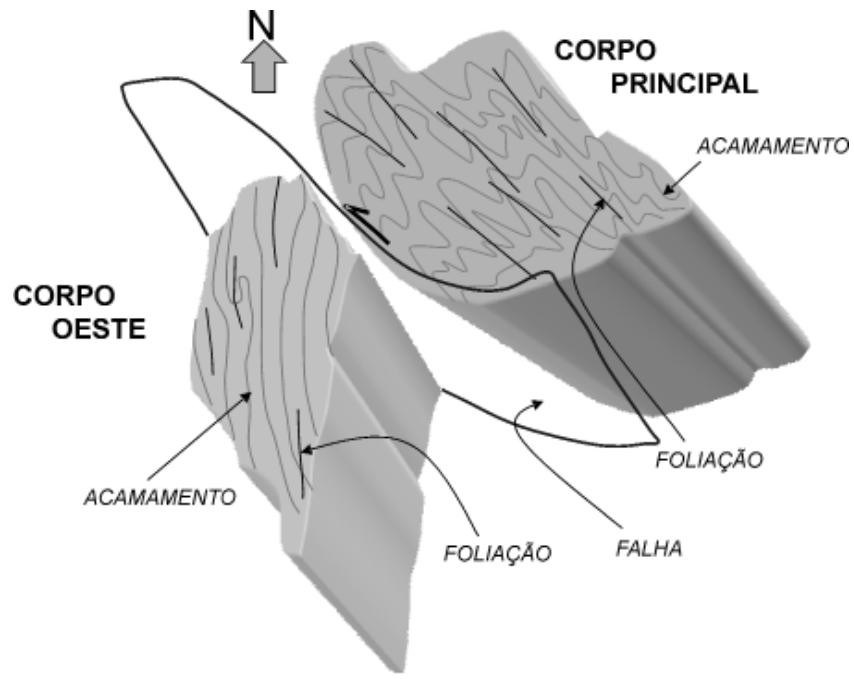

Figura 9 - Bloco diagrama ilustrando a geometria tridimensional dos Corpos de minério Oeste e Principal da Mina de Casa de Pedra. Ver texto para explicação.

peneira de $12,5 \mathrm{~mm}$. A classe de minérios designada de hematítica é definida como sendo constituída por mais que $64 \%$ de teor de ferro. Tais minérios têm sua composição mineralógica composta pelas seguintes fases de minerais: hematita $(75 \%)$, martita $(10 \%)$, magnetita $(2 \%)$, goethita $(8 \%)$, limonita $(3 \%)$ e quartzo $(2 \%)$. Estes minérios têm origem supergênica e apresentam uma porosidade relativamente alta, em média $25 \%$.
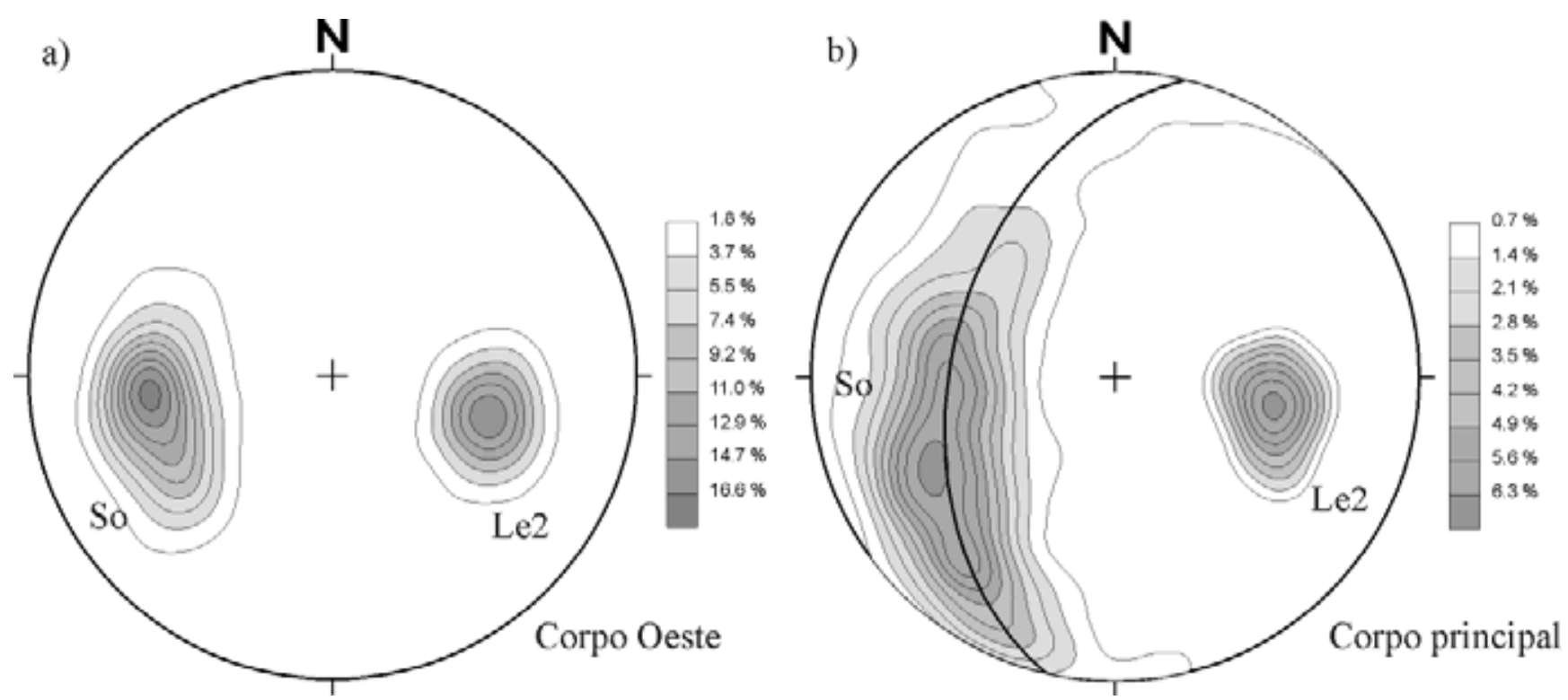

Figura 8 - Diagramas estereográficos evidenciando as diferenças estruturais entre o Corpo Oeste e o Corpo Principal. (a) Acamamento e Lineação de estiramento do Corpo Oeste; (b) Acamamento e Lineação de estiramento do Corpo Principal. (a) Acamamento (So), total de medidas: 1.032, máximo: 084/50 (17\%) e Lineação de estiramento (Le,), total de medidas: 448, máximo: 104/46 (26,8\%), ambos do Corpo Oeste; (b) Acamamento (So), total de medidas: 1.425 , máximo: 064/57 (5,9\%) e Lineação de estiramento (Le $)$, total de medidas: 480, máximo: 100/46 (20,8\%), ambos do Corpo Principal. 
A classe dos minérios designada como itabirítica corresponde a minérios que apresentam porcentagens inferiores a $64 \%$ de teor em ferro. Os minérios itabiríticos são compostos em média pelas seguintes fases minerais: hematita (30\%), martita (18\%), magnetita (4\%), goethita $(12 \%)$, limonita (4\%) e quartzo (32\%), com porosidade média de $16 \%$.

Os minérios hematíticos e itabiríticos apresentam textura variando de granoblástica, ou seja, sem orientação preferencial de forma dos cristais, a lepidoblástica com orientação preferencial de forma. Pode ser observada também a associação entre essas, ou seja, granolepidoblástica, para minérios com baixa orientação preferencial de forma e lepidogranoblástica para minérios com grande parte de suas fases orientadas.

O estudo granulométrico realizado pela medição dos maiores e menores cristais mostrou que a granulometria dos minérios varia de $0,00232 \mathrm{~mm}$ a $0,30021 \mathrm{~mm}$.

Microestruturas Dominantes Minérios pouco deformados apresentam um bandamento que pode ser interpretado como uma reprodução, no mínimo recristalizada, do acamamento sedimentar original (Fig. 10a). As bandas ricas em óxidos de ferro apresentam cristais de hematita granular e martita na forma de porfiroclastos, além de palhetas de hematita especular com orientação preferencial de forma.

A foliação conferida aos minérios pela orientação preferencial da hematita especular tem, em geral, caracter anastomótico. Sombras e franjas de pressão são formadas nas adjacências dos porfiroclastos de magnetita/ martita, dando origem a feições assimétricas e alongadas (Fig. 10b). A proximidade de zonas de cisalhamento é caracterizada pela cominuição progressiva dos porfiroclastos, com a total transformação dos cristais de magnetita em hematita. Podem, ainda, ser observadas estruturas do tipo hematita fish e ribbons de quartzo.

Nas bandas ricas em quartzo, os grãos formam junções tríplice de $120^{\circ} \mathrm{em}$ agregados poligonais, indício de deformação plástica com controle importante da migração de borda de grão (GBM) (Fig. 10a). A formação dos subgrãos está diretamente relacionada com o processo de recuperação do grão deformado, em um estágio que precede a recristalização total do grão.

Nos minérios intensamente deformados, observam-se bandas de hematita especular preferencialmente orientadas, intercaladas com bandas de hematita não orientada. Essas bandas, sem orientação aparente, podem, na verdade, representar o incipiente desenvolvimento de uma clivagem de crenulação.

O estágio de recristalização mais avançado pode ser observado nos minérios com cristais de hematita granular com bordas retas formando uma junção tríplice em agregados poligonais. Esse tipo de contato entre cristais indica uma recristalização estática, tardi a póscinemática do principal evento deformacional atuante na área $\left(\mathrm{E}_{2} / \mathrm{D}_{2}\right)$.

\section{PAPEL DAS ESTRUTURAS DEFORMACIONAIS} NOS ATRIBUTOS DO MINÉRIO A análise de detalhe realizada nos dois corpos de minérios de ferro da Mina de Casa de Pedra mostrou que, do ponto de vista estrutural, os corpos Oeste e Principal são significativamente distintos. Pode-se dizer que os atributos dos minérios provenientes de um ou de outro corpo devem ser também distintos, fato indicado pelos constituintes, texturas e microestruturas presentes.

Mineralogicamente, o Corpo Oeste é caracterizado pelo predomínio de hematita especular e goethita (Fig. 10c), enquanto que o Corpo Principal é constituído dominantemente por hematita granular e magnetita (Fig. 10d). Porcentagens similares das fases martita e limonita foram encontradas em ambos os corpos de minério. O Corpo Oeste apresenta as maiores porcentagens das fases goethita e limonita nos vários tipos de minérios analisados. Isso pode ser justificado pela posição espacial desse corpo, que se encontra muito acima do lençol freático, facilitando a percolação de fluidos meteóricos.

Considerando-se apenas os minérios de alto teor, percebe-se que, no Corpo Oeste, os minérios hematíticos são constituídos pela associação mineralógica hematita especular, martita e goethita, e no Corpo Principal são formados principalmente por hematita granular (Fig. 10d). Nesse caso, porcentagens similares de magnetita foram encontradas.

Analisando-se a porcentagem de poros existentes em cada domínio foi possível observar que o Corpo Oeste apresenta a menor porcentagem de poros, com a média de $17 \%$, enquanto que o Corpo Principal apresenta-se mais poroso, com média de $20 \%$ de poros. A análise da distribuição da porosidade para os diferentes domínios estruturais permitiu concluir que o Corpo Oeste apresenta uma distribuição heterogênea da porosidade (Fig. 10e), enquanto o Corpo Principal apresenta distribuição homogênea da porosidade (Fig. 10f). Durante o estudo petrológico, observou-se que o Corpo Oeste apresenta maior conexão de poros, conferindo à rocha maior permeabilidade e o Corpo Principal apresenta uma menor conexão de poros. A análise granulométrica evidenciou que as fases minerais do Corpo Oeste apresentam granulometria mais grossa quando comparadas ao Corpo Principal. Quanto às texturas observou-se que os minérios do Corpo Oeste apresentam uma tendência a ter orientação preferencial de forma, com textura lepidogranoblástica, enquanto que o Corpo Principal apresenta a tendência de ser granoblástico.

Tais observações comprovam a ideia de que a geometria e as relações estruturais interferem diretamente nos atributos dos minérios de ferro, analisados nesse trabalho. Para o caso do Corpo Oeste, isto se deve à posição que o mesmo ocupava no momento da deformação (na aba oeste do Sinclinal Moeda), de forma que, durante o transporte tectônico para WNW, a foliação $\left(\mathrm{S}_{2}\right)$ desenvolveu-se paralelamente ao acamamento da Formação Ferrífera. Essa relação de paralelismo favoreceu o desenvolvimento dos cristais de hematita 

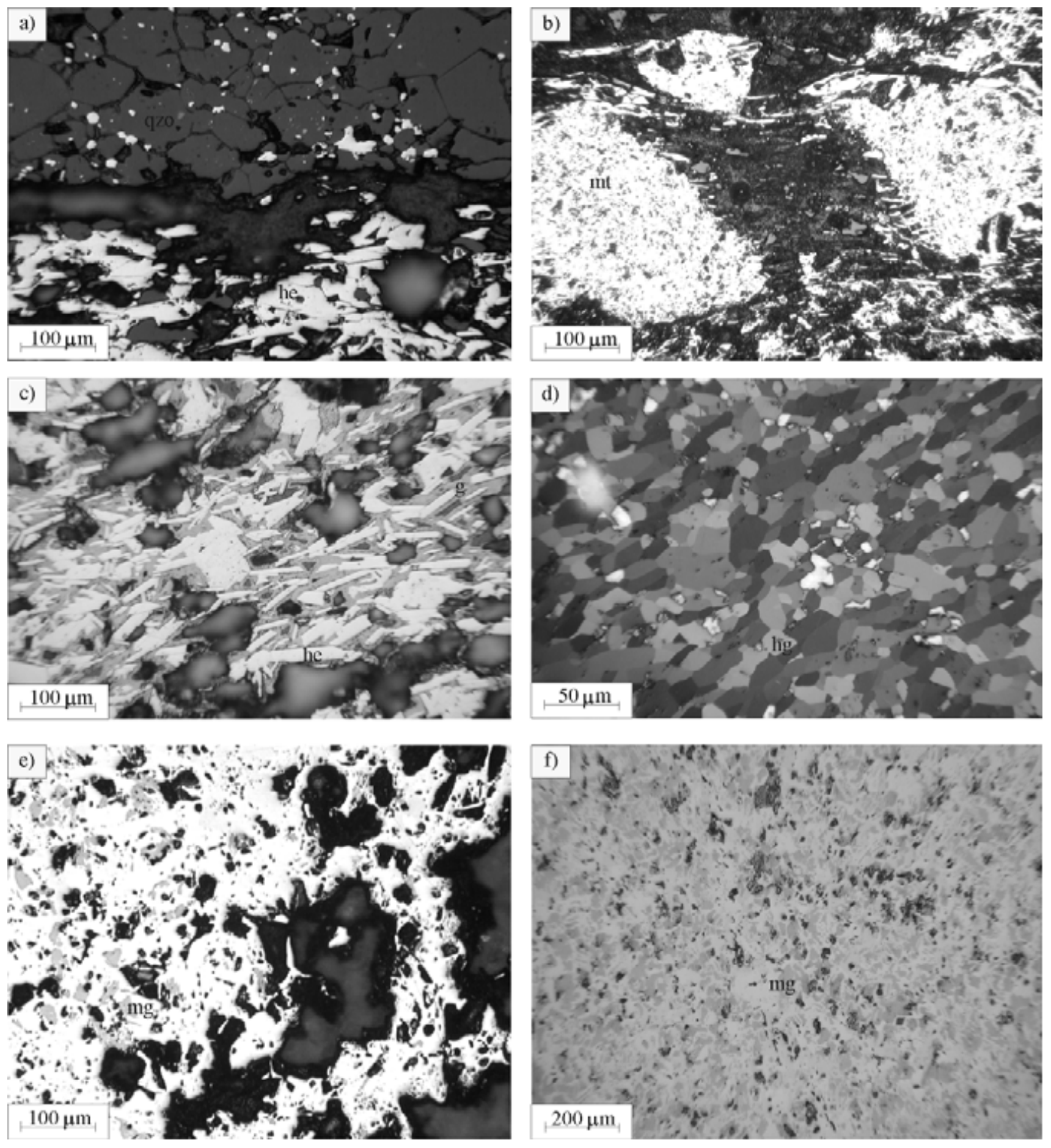

Figura 10 - Fotomicrografias mostrando as diferenças nos atributos intrínsecos dos minérios de ferro. (a) Acamamento definido pela alternância de bandas quartzosas (qzo) e bandas de óxidos de ferro, notar a relação de paralelismo entre a foliação e o acamamento, característica típica do Corpo Oeste. (b) Foliação anastomótica formada por cristais de hematita especular contornando profiroblasto de martita (mt), Corpo Principal. (c) Mineralogia predominante no Corpo Oeste, hematita especular (he) e goethita (g). (d) Mineralogia predominante no Corpo Principal, hematita granular (hg) e magnetita (mg). (e) Distribuição heterogênea da porosidade do Corpo Oeste. (f) Distribuição homogênea da porosidade do Corpo Principal.

especular e o aumento granulométrico de todas as fases ferruginosas. Como o acamamento ficou praticamente preservado ocorreu maior facilidade para a lixiviação das bandas quartzosas, resultando em uma porosidade heterogênea e maior conexão entre os poros, características predominantes no Corpo Oeste.

No caso do Corpo Principal, o bandamento encontra-se marcado por dobras parasíticas truncadas 
pela foliação, marcando uma relação de obliquidade entre estas estruturas. Essa relação deve ter impedido o crescimento dos cristais das fases ferruginosas, mantendo a granulometria geral do Corpo Principal mais fina. Da mesma forma, observou-se que essa relação estrutural deve ter dificultado a lixiviação das bandas quartzosas, dando origem a uma baixa conexão de poros e distribuição homogênea da porosidade. $\mathrm{O}$ fato do Corpo Principal apresentar maior porcentagem de poros $(20 \%)$ pode ser explicada devido à maior quantidade de magnetita existente nesse corpo, que ao se transformar em martita, aumenta a porosidade intragranular do minério.

CONCLUSÕES A partir da análise estrutural de detalhe, realizada na região da Mina de Casa de Pedra, foi possível concluir que a região apresenta dois domínios estruturais controlados por falhas de empurrão curvas e vergentes para W. Analisadas sob o ponto de vista estrutural, as duas frentes de lavra da mina são distintas, sendo o Corpo Oeste caracterizado pela relação de paralelismo entre o acamamento (So) e a foliação $\left(\mathrm{S}_{2}\right)$ e o Corpo Principal caracterizado pela relação de obliquidade entre o acamamento (So) e a foliação $\left(\mathrm{S}_{2}\right)$ em uma região dobrada.

O presente trabalho demonstra que os domínios estruturais distintos das frentes de lavra Corpo Oeste e Corpo Principal apresentam repercussão nas microestruturas, texturas e composição mineralógica de minérios hematíticos e itabiríticos. Da mesma forma, estes domínios estruturais apontam reflexo no comportamento metalúrgico de redução em alto forno do minério granulado da Mina de Casa de Pedra, conforme detalhado por Trzaskos-Lipski (2001). Os resultados, embora assinalem diferenças sutis, demonstram que, mesmo no processo de redução em alto forno, a posição estrutural e composição mineralógica controlam o comportamento metalúrgico dos minérios de ferro.

Agradecimentos Ao CNPq pela concessão da bolsa de mestrado e à Companhia Siderúrgica Nacional - CSN, pelo financiamento e apoio ao projeto. Ao DEGEO/ EM/UFOP pela infraestrutura. A todos os funcionários da CSN que diretamente ajudaram no desenvolvimento deste projeto.

\section{Referências}

Alkmim F.F. \& Marshak S. 1998. Transamazonian Orogeny in the Southern São Francisco Craton Region, Minas Gerais, Brazil: evidence for Paleoproterozoic collision and collapse in the Quadrilátero Ferrífero. Precambrian Research, 90:29-58.

Barbosa O. 1949. Contribuição à geologia do centro de Minas Gerais. Min. e Met. 14(79):3-19.

Bruckner H.K., Cunningham D., Alkmim F.F., Marshak S. 2000. Tectonc implications of Precambian Sm$\mathrm{Nd}$ dates from the southern São Francisco craton and adjacent Araçuaí and Ribeira belts, Brazil. Precambrian Research, 99:255-269.

Carneiro M.A. 1992. O Complexo Metamórfico Bonfim Setentrional - Quadrilátero Ferrifero, Minas Gerais: Litoestratigrafia e evolução geológica de um segmento de crosta continental do Arqueano. Tese de Doutorado, Instituto de Geociências, Universidade de São Paulo, São Paulo, 233 p.

Chemale Jr. F., Quade H., Carbonari F.S. 1987. Economic and structural geology of the Itabira Iron District, Minas Gerais, Brazil. Zbl. Geol. Palaont. Teil., 1(7/8):743-752.

Chemale Jr. F., Rosière C.A., Endo I. 1991. Evolução tectônica do Quadrilátero Ferrífero, Minas Gerais. Um modelo. Rev. Pesquisas UFRS, 18:104-127.

Dorr J.V.N. 1969. Physiographic, Stratigraphic and Structural Development of the Quadrilatero Ferrifero, Minas Gerais, Brazil. Washington, Geological Survey Professional Paper 641-A, 110 p.

Eichler J. 1976. Origin of the Precambrian Iron Formation. In: Wolf K.H. (ed.) Handbook of strataboud and stratification ore deposits. New York, Elsevier, p. 157-201.

Endo I. 1988. Análise Estrutural Qualitativa do Minério de ferro e encaixantes da Mina de Timbopeba-Borda Leste do Quadrilátero Ferrífero, Mariana, MG. Dissertação de Mestrado, Escola de Minas, Universidade Federal de Ouro Preto, Ouro Preto, $111 \mathrm{p}$.

Endo I. 1997. Regimes Tectônicos do Arqueano e Proterozóico no interior da Placa Sanfranciscana: Quadrilátero Ferrifero e Áreas Adjacentes, Minas Gerais. Tese de Doutorado, Instituto de Geociências, Universidade de São Paulo, São Paulo, 243 p.

Endo I. \& Nalini Jr. H.A. 1992. Modelo da evolução cinemátia do Sinclinal Alegria e adjacências, Quadrilátero Ferrífero - MG. Rev. Esc. de Minas, 45(1/2):24-27.

Guild P.W. 1953. Iron Deposits of the Congonhas District, Minas Gerais, Brazil. Econ. Geology, 48:639-676.

Guild P.W. 1957. Geology and Mineral Resources of the Congonhas District, Minas Gerais, Brazil. Washington, Geological Survey Professional Paper 290, 90 p.

Guimarães D. \& Belezkij V. 1953. Notas sobre a Geologia Estrutural de Casa de Pedra, Congonhas do Campo, Minas Gerais. Bol. Inst. Tecnol. Industrial do estado de Minas Gerais, 15:45-60.

Hacksparcker P.C. 1979. Strukturelle und texturelle Untersuchungen zur internen Deformation des Eisenreichrzörpers der Grube Águas Claras bei Belo Horizonte/Minas Gerais/Brasilien. Clausthal-Zellerfeld, Clausthaler Geologische Abhandlungen, 164 p.

Hippertt J.F., Borba R.P., Nalini Jr. H.A. 1992. O contato Formação Moeda-Complexo Bonfim: Uma zona de cisalhamento normal na borda oeste do Quadrilátero Ferrífero, MG. Rev. Esc. de Minas, 45(1/2):32-34.

Ladeira E.A., Siqueira L.T., Souza L.A.C., Hashizume B.K., Oliveira J.J.C. 1997. Mapeamento Geológico das Cava Principal e Oeste e entorno da Mina de Casa de Pedra. São Paulo, CSN, Relatório Interno, 40 p. 
Lagoeiro L. \& Romano R. 2000. Microstructures indicative of intracrystalline plasticity in microboudinaged quartz veins. Revista Pesquisa \& Pós-Graduação, 2(2):12-17.

Leone R.D., Piancino E.J., Montoro A., Gonzales J.M., Grassi R.C., Etchevarne P.R. 1981. Evaluacion tecnica de minerales calibrados para reduccion direta. In: ILAFA-IVES, Seminario ILAFA-IVES de Reduccion y Fusion Directa, 6, Anais, p. 1-57.

Lipski M., Endo I., Castro P.T.A, Trzaskos-Lispki B. 2001. Estudo do Campo de Tensões do Cenozóico no Quadrilátero Ferrífero, Minas Gerais. In: SBG, International Symposium on Tectonics of the Brazilian Geological Society, 8, Anais VIII SNET, p. 331-333.

Marshak S. \& Alkmim F.F. 1989. Proterozoic contraction/ extension tectonics of the Southern São Francisco Region, Minas Gerais, Brazil. Tectonics, 8(3):555-571.

Marshak S., Alkmim F.F., Evangelista H.J. 1992. Proterozoic Crustal Extensional and the Generation of Dome-andKeel granite-greenstone Terrane. Nature, 357:491-493.

Noce C.M. 1995. Geocronologia dos eventos magmáticos, sedimentares e metamórficos na região do Quadrilátero Ferrifero, Minas Gerais. Tese de Doutorado, Instituto de Geociências, Universidade de São Paulo, São Paulo, $128 \mathrm{p}$.

Rosière C.A. 1981. Strukturelle und texturelle Untersuchungen in der Eisenerzlagerstatte "Pico de Itabira" bei Itabirito/ Minas Gerais, Brasilien. Dissertationen, Technischen Universität Clausthal, Clausthal-Zellerfeld, 302 p.

Rosière C.A. 1992. A recristalização do minério de ferro da jazida o Pico de Itabirito no Quadrilátero Ferrífero, MG e sua implicações genéticas. In: SBG, Simpósio de Geologia de Minas Gerais, 2, Anais, p. 173-186.

Rosière C.A., Chemale Jr. F., Guimarães M.L.V. 1995. Um modelo para a evolução microestrutural dos minérios de ferro do Quadrilátero Ferrífero. Parte I - Estruturas e Recristalização. Geonomos, 1(1):65-84.

Santiago T.C. 2000. Caracterização Química e Estrutural do Minério de Ferro Sinter Feed - Avaliação Técnica em
Sinterização Piloto Utilizando Minérios da Porção Leste do Quadrilátero Ferrífero. Dissertação de Mestrado, Instituto de Geociências, Universidade Federal de Minas Gerais, Belo Horizonte, 116 p.

Stephenson R.L. 1980. Direct Reduced iron-tecnology and economics of production and use. Chicago, The Iron \& Steel Society, $243 \mathrm{p}$.

Teixeira W. 1982. Geochronology of Southern part of São Francisco Craton. Rev. Bras. Geoc., 12(1-3):268-277.

Trzaskos-Lipski B. 2001. Atributos estruturais do minério de ferro granulado da Mina de Casa de Pedra e sua influencia no processo de redução em alto-forno. Dissertação de Mestrado, Escola de Minas, Universidade Federal de Ouro Preto, Ouro Preto, 136 p.

Varajão C.A.C., Ramanaidou E., Colin F., Nahon D. 1996. Martitização: Alteração Supergênica da Magnetita. Rev. Esc. Minas, 50(3):18-20.

Varajão C.A.C., Ramanaidou E., Colin F., Nahon D. 1997. Gênese dos corpos de hematita compacta "hard hematite ores": metassomatismo, sedimentação ou alteração supergênica?. Rev. Esc. Minas, 50:40-43.

Xavier E.M. 1994. Relação entre o processo de redução direta e os atributos estruturais e texturais do minério de ferro granulado da Mina da Mutuca - Belo Horizonte, MG. Dissertação de Mestrado, Departamento de Geologia da Escola de Minas, Universidade Federal de Ouro Preto, Ouro Preto, 164 p.

Zavaglia G. 1995. Condicionantes geológicos do comportamento dos minérios de ferro do depósito de Tamanduá (MG) no processo metalúrgico de redução direta. Dissertação de Mestrado, Departamento de Geologia da Escola de Minas, Universidade Federal de Ouro Preto, Ouro Preto, 200 p.

Manuscrito ID 21190

Submetido em 05 de abril de 2011 Aceito em 18 de agosto de 2011 